\title{
Study on Resource Management for Prefabricated Concrete Building Based on BIM Technology
}

\author{
$X U$ Ning $^{1,2, *}$, Wang Guangbin ${ }^{1}$ \\ ${ }^{1}$ Tongji University, Economics and Management School, 200092, Shanghai, China \\ ${ }^{2}$ Shanghai Ershiye Construction Co., Ltd, 201999, Shanghai, China
}

\begin{abstract}
A comparative analysis of resource management elements between PC (Prefabricated Concrete) structure and traditional cast-in-place structure was carried out firstly. Based on BIM (Building Information Modeling) technology, the resource management elements such as labour, materials and machinery for PC building were analyzed detailedly. It was shown that the dynamic and rational allocation of labour in the narrow work plan for PC building can be realized by the labour deployment method proposed in this paper; the adjustment time of the inclined bracing system for PC building can be reduced to a large extent by the this turnover method proposed in this paper; and the problem of arrangement and selection of tower crane for PC building can be solved by the analysis method of tower crane proposed in this paper.
\end{abstract}

Resource management includes a series of activities such as planning, organization, command, coordination and control of the labour, materials, machinery, technology, capital and infrastructure required for the project ${ }^{[1]}$. Project resource management is a very important part of the construction project ${ }^{[2,3]}$. The project objectives can be realized successfully by the optimal allocation of resources and dynamic control.

PC buildings have developed rapidly in recent years because of their production in the factory, on-site installation, less construction period, less on-site wet operations, better environmental protection and less material waste. Due to the difference of organizational mode, the allocation of elements of PC building is very different from the traditional building. The resource management of PC building has become one of the problems needs to be solved.

Considering the BIM technology, this paper analyzed the resource management elements of labour, materials and machinery of PC building. Many useful conclusions will provide a reference for the implementation of post similar projects.

\section{Difference of resource management element}

The main differences of elements between the PC building and the traditional building are shown in Table 1.

\footnotetext{
Corresponding author: 123xn@tongji.edu.cn
}

As can be seen from the table 1, the number of workers and the types of work in PC buildings are greatly reduced, and the types of new machinery are increased.

Table 1. Difference of resource management element

\begin{tabular}{|l|l|l|l|}
\hline $\begin{array}{c}\text { No } \\
\cdot\end{array}$ & $\begin{array}{c}\text { Resource } \\
\text { manageme } \\
\text { nt elements }\end{array}$ & \multicolumn{1}{|c|}{$\begin{array}{c}\text { Traditional } \\
\text { building }\end{array}$} & \multicolumn{1}{c|}{$\begin{array}{c}\text { PC } \\
\text { Building }\end{array}$} \\
\hline 1 & labour & $\begin{array}{l}\text { bricklayer, } \\
\text { wood worker, } \\
\text { steel worker, } \\
\text { shelf worker }\end{array}$ & $\begin{array}{l}\text { assembly } \\
\text { worker }\end{array}$ \\
\hline 2 & materials & $\begin{array}{l}\text { Steel bar, } \\
\text { concrete, } \\
\text { Masonry, sand, } \\
\text { water }\end{array}$ & $\begin{array}{l}\text { component } \\
\text { finished semi- } \\
\text { products, } \\
\text { sealant }\end{array}$ \\
\hline 3 & machinery & $\begin{array}{l}\text { tower crane, } \\
\text { steel processing } \\
\text { machinery, } \\
\text { concrete tanker }\end{array}$ & $\begin{array}{l}\text { tower crane, flat } \\
\text { transport, } \\
\text { mould, inclined } \\
\text { bracing }\end{array}$ \\
\hline
\end{tabular}




\section{BIM technology}

Based on three-dimensional digital technology, BIM technology integrates engineering data models of various related information in different stages of project through the unified IFC standard ${ }^{[4,5]}$.

According to the BIM model, the rich construction information can be obtained, which is beneficial to optimize the construction process, and can manage the construction resources such as labour, materials, and equipment, and it improve the overall construction efficiency and construction quality of the project.

The BIM model established by Revit software for PC building is as follows Fig.1 and Fig.2, in which the PC components are green.

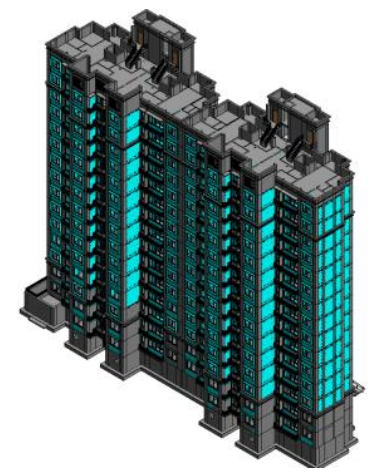

Fig. 1. The whole BIM model for PC building

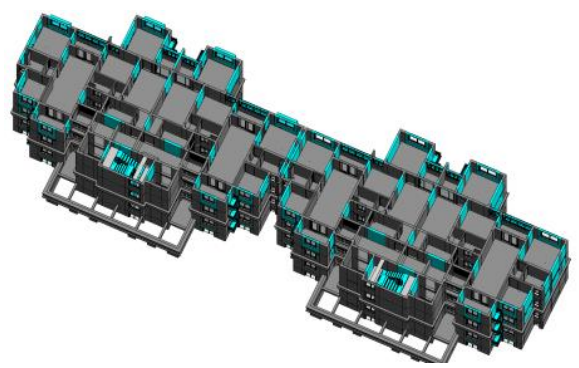

Fig. 2. The sectional view of model for PC building

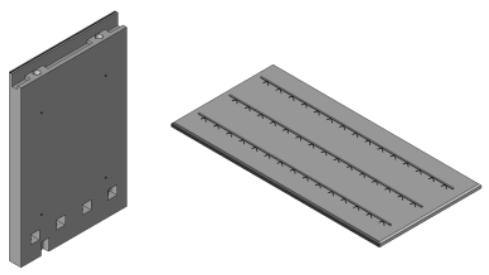

Fig. 3. PC components

\section{Labour management based on BIM technology}

During the stage of construction for PC building, the labour resources are generally arranged according to the construction planning, site conditions and progress conditions ${ }^{[6]}$.
Since the construction procedure of PC building is cross-dense and the flow section is less divided, the construction workers often concentrate on the specific area to complete the task.

Being the insufficient work area, it can't exert the maximum effectiveness of the construction team, which severely limited the speed of prefabricated building construction. Therefore, a method of labour deployment for PC building based on BIM technology is provided as follows:

1) Obtain the position of the field workers by means of on-site positioning;

Positioning chips are set in the helmet of the operation personnel on site, and the operator wears the helmet to the site for construction operation according to regulations. Several positioning devices are arranged on the four sides of the PC building, and a Wi-Fi network is arranged to enable the signals transmitted by the positioning device to cover each corner of the building.

2) Establish a 3D BIM model for PC building according to the drawings;

3) Update the position of the field workers in real time and draw the action trajectory to display in the $3 \mathrm{D}$ model;

Through establishing a data connection between the positioning device around the building and the positioning chip in the helmet; the trajectory of the field workers can be recorded in the plane of the standard level of the fabricated building

4) Simulate the three-dimensional installation process of the PC components using the BIM software;

5) Match the operator's action trajectory with the process of three-dimensional installation of $\mathrm{PC}$ components, and obtain the real-time statistics of the labour force resources for PC building;

6) Obtain and display the labour-intensive area and labour-insufficient area according to statistical data Areas and areas with;

7) Redistribute the labour area between the labourintensive area and the labour-insufficient area to balance the labour distribution.

The 3D model focuses on areas with density concentration and insufficient working area. For example, the density standard is $3 \mathrm{~m}^{2}$ per person for this area. When the working density is less than $3 \mathrm{~m}^{2}$, the area is marked with red; the working density of the whole layer is calculated and marked with different colours.

According to the needs of three-dimensional component hoisting, labour density can be adjusted to make it larger than $3 \mathrm{~m}^{2}$, and working resources are arranged to the designated free area for parallel operation. 
Compared with the existing technology, the method has the advantages of real-time simulation, dynamic correlation, and reasonable accuracy.

\section{Materials management based on BIM technology}

There are many revolving materials in the PC building, and the supporting system is one of turnover materials in the PC building ${ }^{[7]}$.

The support system of PC building mainly consists of independent support for superimposed slab, bracing support for prefabricated wall slab, and diagonal bracing for cast-in-place formwork, etc. It is a kind of turnover material with a larger amount except the split components of PC building. In the detailed design drawing, due to the difference of the positions of the preembedded rings, the adjustment lengths of diagonal bracing are different. At present, when the diagonal bracing is disassembled and transported to the upper floor, the operator picks it up without any classification. It needs to be adjusting the length of the diagonal bracing according to the position of the embedded part of the wall. The work efficiency is greatly reduced.

Meanwhile, multiple sets of support systems will be equipped with the height of PC building, and the disassembly and turnover will be carried out according to the time for concrete strength of different parts. Sometimes, the workers will be confused with the disassembly time and disassembled earlier, which will lead to a safety hazard.

So the turnover of the support system for PC building support system affects the schedule and safety of the PC building.

Therefore, a rapid turnover method of support system for PC building based on BIM technology is provided as follows:

1) Establish a three-dimensional BIM model of PC building;

2) Determine the three types of components in PC building: independent support for superimposed slab, bracing support for prefabricated wall slab, and diagonal bracing for cast-in-place formwork;

3) Determine the size categories of diagonal bracing;

4) Arrange the three types diagonal bracing in the standard layer of the three-dimensional BIM model;

5) Mark the components at different positions and make two-dimensional code label correspondingly;

6) Attach the two-dimensional code label to the PC components on the first floor of the PC building;

7) Transport the support system to the corresponding installation location on the next level according to the information of the two-dimensional code label.

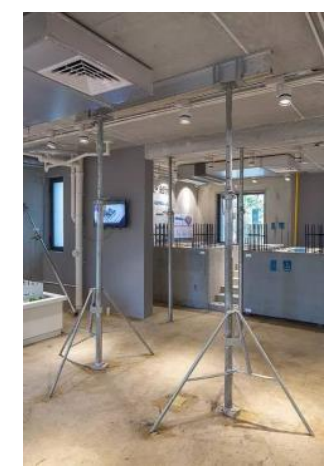

Fig. 4. Bracing support in site

The two-dimensional code label adopts different colours to distinguish three types of components. The independent support for superimposed slab, bracing support for prefabricated wall slab, and diagonal bracing for cast-in-place formwork respectively correspond to one colour correspondingly.

Otherwise, the two-dimensional code tag includes a two-dimensional code and a LOGO identifier, the twodimensional code includes attribute information of each component, and the LOGO indicates tag information including each component.

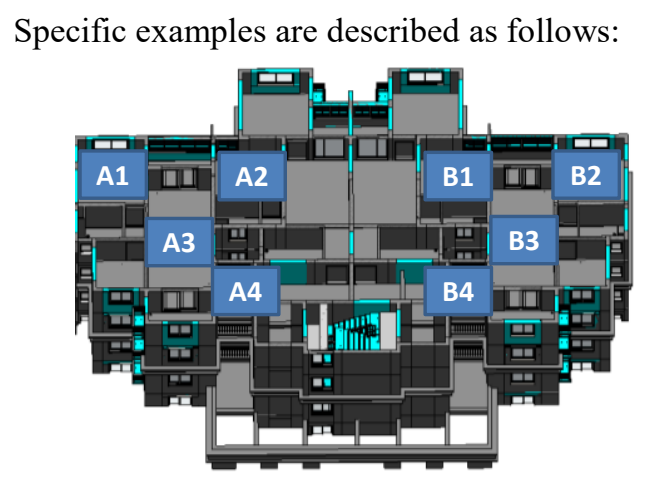

Fig. 5. Room division at the standard level

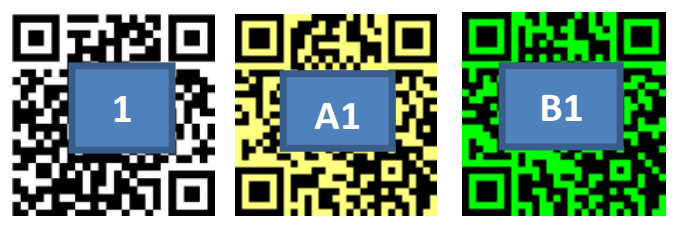

Fig. 6. Different types of label

From Fig.5 and Fig.6, the room numbers are identified in English capital letters, such as rooms A, B, $\mathrm{C}$, D, etc. When the room exceeds 26, the two English capital letters are used, such as AA, AB, AC, etc. The independent support of the slabs is classified according to the information of the turnaround time, and it is represented by the Arabic numerals 1, 2, 3, etc.; the PC wall slab support and the cast-in-place slant support member model store the room and the length. It is sorted by the length value, which described as A1, A2, A3, B1, B2, B3, etc. The two-dimensional code labels independently supported by the laminated floor are indicated by black, and the Arabic numerals 1, 2, 3, etc. located in the middle of LOGO indicate the number of 
turnovers. The two-dimensional code of bracing support and the cast-in-place template bracing support of the PC wall panel are used red and yellow colours to indicate respectively. The uppercase English and Arabic numerals displayed in the middle of the two-dimensional code such as the red A1, A2, A3, etc. indicate different types of $\mathrm{PC}$ wallboard bracing supports in different rooms, yellow A1, A2, A3, etc. indicate the different types of bracing support of the cast-in-place formwork in different rooms, that is, the different types of diagonal support lengths in different rooms.

Using the turnover method of support system for PC building, the support system are scientifically classifies according to time and space domain.

The identification of two-dimensional code + colour + LOGO is used in the classification and identification system, which truly realizes the classified transportation and hoisting, and greatly reduces the adjusting time of bracing support.

Based on the above ideas, a turnover device is developed to sovle the problem of quick turnover and safe hoisting. The device is described as follows:

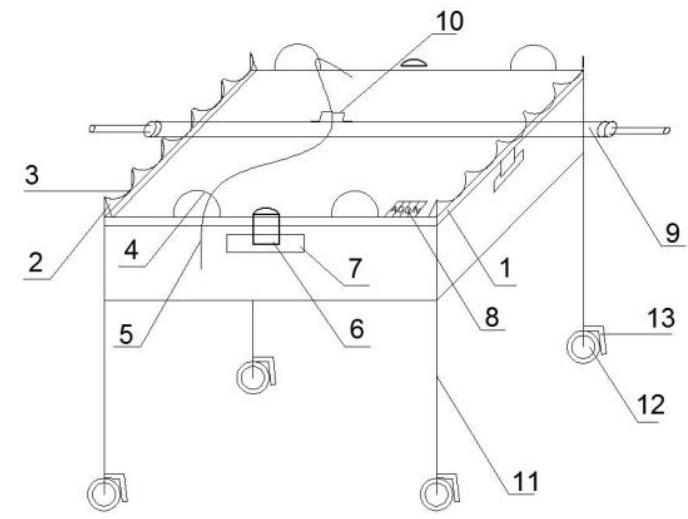

Fig. 7. Device of quick turnover and safe hoisting

There are many parts in the device such as steel plate (1), end slot (2), slot (3), lifting ring (4), cable (5), clamping ring (6), clamping ring (7), encoder (8), inclined support (9), inclined support handle (10), carriage frame (11), roller (12), brake parts (13).

\section{Machinery management based on BIM technology}

In the PC building, due to the large weight of PC components such as prefabricated walls, slabs and stairs, the layout and selection of tower cranes is a problem, which should be paid more attention ${ }^{[8]}$.

The existing layout method of tower crane based on BIM technology mainly establishes the lifting member model and the tower crane model to carry out the weight inspection of the lifting members in the tower crane range. Therefore, the hoisting weight can be optimized within the allowable arm length range of the tower crane, and the hoisting weight can be arranged reasonably. Otherwise, the existing layout method of tower crane mainly focus on the plane layout, other factors such as the vertical height of the tower crane, the safety calculation of foundation of the tower crane, and the economic analysis of the tower crane model Should be fully considered. As the indispensable basic component in the PC building, the prefabricated components are the heaviest component in the construction site. It can't be optimized like the traditional tower crane to reduce the hoisting weight.

Actually, the layout of the tower crane of PC building is a reverse and completely different process with traditional layout method. It need to be carried on a special layout plan of the tower crane for PC buildings. Therefore, a method of layout and selection method of tower crane for PC building based on BIM technology is provided as follows:

1) Establish a three-dimensional overall BIM model for PC building according to the PC drawings;

2) Select preliminarily the type of tower crane;

3) Obtain the data of safety performance and reinforcement of the tower crane after preliminary selection;

4) Optimize the selection type of tower cranes, and obtain the best type of tower cranes according to safety performance, foundation type of tower crane and reinforcement data.

5) Complete the layout of the tower cranes for PC building.

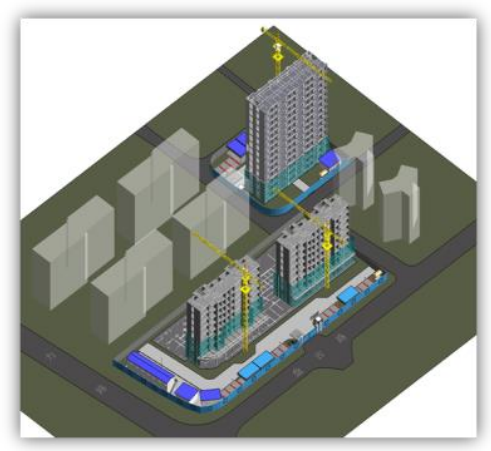

Fig. 8. Arrangement of tower crane for PC building

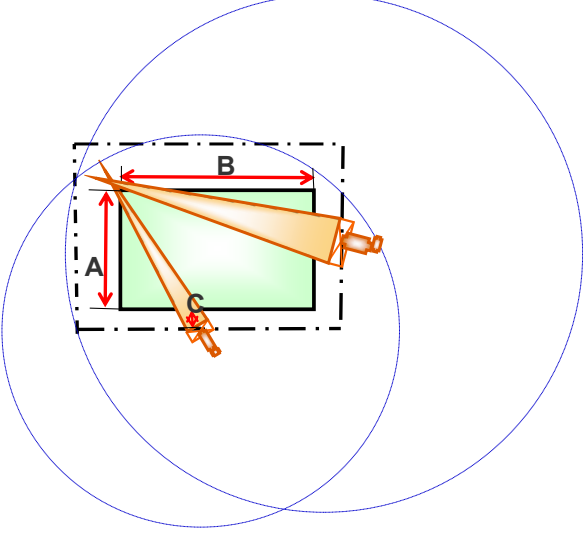

Fig. 9. Trajectory and envelope diagram of tower crane 
Surrounding with the key factor of the hoisting weight of PC building component, through the drawing of the trajectory envelope diagram of the tower crane, the hoisting weight and the arm length of the tower crane are regarded as important constraints of the tower crane, Combined with the vertical Implicit parameters, safety calculations, economic calculations of tower crane, the suitable safe and economical layout plan and selection content of tower crane for PC building are obtained.

In this way, the layout and selection method of tower crane for PC building can be determined reasonably, accurately and timely.

\section{Conclusion}

1) It is very important to classify the composition of operating personnel. After determining the type of work of component installation, the data of classified operating personnel can be correlated with the procedure of component installation.

2) The label reading of two-dimensional code + colour + LOGO and the device development can achieve the rapid turnover of support system for PC building.

3) The height of the tower crane is determined according to the height of the PC building and the vertical dimension and safety distance of the top lifting member. The walking envelope of tower crane is a closed line, which parallel to the outer edge of the building.

\section{References}

1. J.J. Zhang. Research on resource allocation management during project construction. Technology Innovation and Application, 1, 7 (2014)

2. S.N. Thomas, D.X.M. Zheng, J.Z. Xie. Allocation of construction resources through a pull-driven approach. Construction Innovation: Information, Process, Management. 1, 77 (2013)

3. X.L. Li. The reach of construction enterprises dynamic multi-project management resource allocation. Xi'an University of Architecture and Technology, (2012)

4. J. G. Ricardo, A. Grilo. Building information modeling and interoperability. Automation in Construction, 11, 387 (2009)

5. C.S. Sun, F. Jiang, Q.P. Man. A summary on BIM application in construction industry. Journal of Engineering Management, 3, 27 (2014)

6. F. Zhou. Reasearch on the optimization of construction resource allocation based on BIM. Guangzhou University, (2016)

7. N. Zhao, M.L. Sun, D.J. Du. Application of BIM formwork in material control of rotating frame, Tianjin Construction Science and Technology, 6, 37 (2017)
8. Y. Wan. Application management and control of group tower crane based on BIM technology. Building Construction, 9, 1643 (2018) 